\section{BCG in cancer}

Like that of any other disease, the management of cancer requires a logical approach. Unfortunately much of the immunotherapy of malignant disease has escaped this dictum, since the wilder concepts were already in vogue early in this century. The rationale for immunotherapy had to await the identification of tumour-specific antigens in transplantable tumours in syngeneic animal populations. ${ }^{1-3}$ Although the protective effects of immunising these animals against their own tumours has been shown time and again, the application of these findings to tumours arising spontaneously in animals and man is far less clear. In such cases investigations have failed to show tumour-specific antigens; and their existence would be irrelevant to treatment if once identified they proved to be non-immunogenic. Nevertheless, specific active immunotherapy has been often given on the presumption that such antigens do exist. Frequently this has been combined with BCG in the belief that this gives a non-specific boost to the specific anti-tumour response. Just how useful the specific immune response is in terms of treatment is difficult to assess, but many studies now suggest that some benefit is attributable to the activity of BCG.

Bacterial toxins have been used in treating cancer for many years with sporadic success. ${ }^{4}$ BCG was found to have a potent immuno-stimulatory effect on responses to heterologous antigens $^{5-7}$ and is known to evoke a wide range of changes in the host. These include non-specific stimulation of activity of the reticuloendothelial system ${ }^{8}$-and a concomitant increase in the numbers of macrophages in the spleen, liver, and lungs"; localised changes in tissue at the site of injection ${ }^{10}$; activation of macrophages ${ }^{11}$; release of interferon ${ }^{12}$; increased phagocytosis; and enhanced homograft rejection. ${ }^{13}$

Many workers have found that direct injection of BCG into established tumours may cause regression of tumours and elimination of tumour cells from regional lymph nodes, while injection at a distant site is far less effective. Animal studies of the latter have shown enhancement, reduction, or no change in growth after injection of BCG. It has been presumed that when there is minimal residual disease inoculating BCG may lead to increased tumour-directed immune reactivity. If a tumour-specific immune response exists, this may exert a controlling effect on the tumour-but immune manipulation may also facilitate its growth.

The relevance of an intact immune response to therapeutic benefit in malignant disease treated with BCG is not yet clear. Nevertheless, nearly all responses in patients treated in this way have occurred where crudely tested delayed hypersensitivity mechanisms have been intact. The crucial question seems to be whether tumour-specific antigens are present, important, or even relevant to the response seen after treatment with BCG. A recent review ${ }^{14}$ has suggested that for BCG to be effective there must be few tumour cells; the host must be able to develop an immune response to microbial antigens; and adequate numbers of BCG organisms must be injectedand that these are most effective when closely associated with the tumour cells. Whether or not tumour cells need to be immunogenic is still not clear. ${ }^{15-17}$

Animal studies have shown that pretreatment with BCG may delay the appearance of tumours induced by carcinogens and viruses. Once the tumours have developed its influence on growth is variable. A comparable variation may exist in man: possibly BCG vaccination in childhood may reduce the incidence of acute leukaemia. ${ }^{18}$ Other reports present conflicting interpretations, however, so that we do not know whether vaccination in childhood with BCG does in fact reduce the risk of mortality from acute leukaemia. Again, while immunotherapy with BCG or with BCG together with allogeneic leukaemic cells was reported to prolong disease-free survival in patients in remission from acute lymphoblastic leukaemia, ${ }^{19}$ subsequent trials have failed to substantiate this. In acute myelogenous leukaemia various trials suggest that survival may be prolonged. ${ }^{20} 21$

Probably one of the most important effects of BCG is to activate macrophages non-specifically. There is now good evidence of non-immunologic recognition and destruction of malignant cells by activated macrophages, while normal contact-inhibited cells remain undamaged. ${ }^{22}$ Meanwhile the relative harmlessness of $\mathrm{BCG}$, its ready availability, and its theoretical capability for potentiating the host's antitumour response have encouraged its widespread and uncritical use. Recent reports ${ }^{23}{ }^{24}$ have added to an ever-growing number of studies in which BCG given regionally was cast in the crucial role of scavenger of minimal residual disease. Nevertheless, if the potential benefits of BCG used in malignant disease are to be fully realised, further carefully controlled trials must be carried out in conjunction with laboratory studies aimed at elucidating the mechanisms by which it might act.

1 Gross, L, Cancer Research, 1943, 3, 326.

2 Foley, E J, Cancer Research, 1853, 13, 835.

${ }^{3}$ Prehn, R T, and Main, J M, Fournal of the National Cancer Institute, 1957, 18, 769.

4 Nauts, H C, New York Cancer Research Institute Monograph 8, 1969.

5 Lewis, P A, and Loomis, D, Journal of Experimental Medicine, 1924, 40, 503.

${ }^{6}$ Dienes, L, and Schoenheit, E W, fournal of Immunology, 1930, 19, 41.

' Freund, J, Advances in Tuberculosis Research, 1965, 7, 130.

Weiss, D W, Nature, 1960, 186, 1060.

${ }^{9}$ Biozzi, G, et al, Annales de l'Institut Pasteur, 1954, 87, 291.

${ }^{10}$ Alexander, P, National Cancer Institute, Monographs 1973, 39, 127.

${ }^{11}$ Evans, R, and Alexander, P, Nature, 1972, 236, 168.

12. Salvin, S B, Youngner, J S, and Lederer, W H, Infection and Immunity, 1973, 7, 68.

${ }^{13}$ Balner, H, Old, L J, and Clarke, D A, Proceedings of the Society for Experimental Brology and Medicine, 1962, 109, 58.

${ }^{14}$ Bast, R C, et al, New England fournal of Medicine, 1974, 290, 1413.

${ }^{15}$ Baldwin, R W, and Pimm, M V, British Fournal of Cancer, 1973, 27, 48.

${ }^{16}$ Parr, I, British Fournal of Cancer, 1972, 26, 174.

17 Bartlett, G L, and Zbar, B, Fournal of the National Cancer Institute, 1972, 48, 1709.

18 Davignon, L, et al, Lancet, 1970, 2, 638.

19 Mathé, G, British Medical fournal, 1969, 4, 7.

20 Powles, R L, et al, British fournal of Cancer, 1973, 28, 365.

21 Gutterman, J U, et al, Lancet, 1974, 2, 1405.

2:2 Hibbs, J B, Science, 1973, 180, 868.

2:3 Eilber, F R, et al, New England Fournal of Medicine, 1976, 294, 237.

${ }^{24}$ McKneally, M F, Maver, C, and Kausel, H W, Lancet, 1976, 1, 377.

\section{Cerebral blood flow in dementia}

Not long after the nitrous oxide method of measuring blood flow through the cerebral hemisphere $(\mathrm{CBF})$ was introduced by Kety and Schmidt in $1945^{1}$ reports ${ }^{2-4}$ began to appear of reduced flow in patients with organic dementia. Interest in the subject then waned until recently, when the facility for measuring regional cerebral blood flow by injection of isotopes into the internal carotid artery ${ }^{5}$ and the finding that focal increase in regional flow could be related to specific neurological and psychological activity stimulated new research. There was shown to be a focal increase in blood flow over the motor cortex during exercise of the contralateral $\mathrm{arm}^{6}{ }^{6}$ and a general 
increase in flow through the grey matter, maximal in the suprasylvian region, during mental testing with digit span backwards. ${ }^{7}$ The normal resting regional flow pattern ${ }^{8}$ was also found to change during speaking and reading. ${ }^{9}$

These changes, it should be emphasised, were qualitative rather than quantitative-the degree of change, case to case variation, and difficulty in establishing satisfactory controls have made statistical analysis difficult. Nevertheless, focal cerebral activity clearly is reflected in an increase in blood flow through the area concerned, presumably because of increased metabolic demands.

Meantime attention has been turned anew to blood flow in the cerebral hemispheres in disease. Both this and the amount of grey matter have been found to be reduced in senile and presenile dementia, ${ }^{10-12}$ with some suggestion of a difference in the regional pattern between the two groups. Comparison of dementia due to Alzheimer's disease with that caused by cerebrovascular disease showed a somewhat greater reduction of flow in the former. ${ }^{13}$ Again, it has been difficult to interpret these results because of uncertainty about the precise nature of the cases studied. Separation of patients with dementia by age has little meaning, both vascular and primary degenerative lesions being present in both groups. Nevertheless, careful assessment of the clinical features does permit a pathological diagnosis to be made in life with high probability that it will be correct $;^{14-16}$ and when this has been done blood flow in the cerebral hemispheres has been found to be lower in vascular than in primary degenerative dementia in patients of the same age and with the same degree of dementia. ${ }^{17} 18$

Of particular importance is the fact that the reactivity of the cerebral vessels to changes in arterial $\mathrm{PCO}_{2}$ is preserved ${ }^{1217}$ both in primary degenerative and vascular cases. The commonly used term "arteriosclerotic dementia" is misleading, suggesting as it does that the primary defect lies in the walls of the cerebral arteries. While arteriosclerotic changes are certainly present in vascular dementia, the critical lesions are the many small infarcts; for this reason it has been proposed that the condition be known as multi-infarct dementia. ${ }^{19}$ The impaired blood flow seems to be a consequence of rather than the cause of the cerebral atrophy which is present. Attempts have also been made to correlate the regional cerebral blood flow with the type of disturbance affecting the dement (predominantly personality change or impaired cognition function) with results that are somewhat unconvincing. ${ }^{20-22}$

The place of flow measurements in the clinical management of patients with dementia remains to be assessed. As there is no specific treatment for the Alzheimer and multi-infarct types of dementia it could be argued that there is no advantage in measuring blood flow. This view overlooks the fact that attempts to develop satisfactory treatment can succeed only if they are based on certainty of diagnosis. While, then, measurement of blood flow in the cerebral hemispheres must at present be restricted to certain centres, it should (particularly when combined with other new diagnostic techniques such as EMI-scanning) become a necessary step in renewed attempts to assess and treat this distressing condition.

\footnotetext{
${ }^{1}$ Kety, S S, and Schmidt, C F, American fournal of Physiology, 1945, 143, 53.

2 Freyhan, F A, Woodford, R B, and Kety, S S, fournal of Nervous and Mental Diseases, 1951, 113, 445.

${ }^{3}$ Fazekas, J F, et al, fournal of Gerontology, 1953, 8, 137.

4 Lassen, N A, Munck, O, and Tottery, E R, Archives of Neurology and Psychiatry, 1957, 77, 126.

5 Ingvar, D H, and Lassen, N A, Acta Physiologica Scandinavica, 1962, 54, 325.

${ }^{6}$ Olesen, J, Brain, 1971, 94, 635.

7 Ingvar, D H, and Risberg, J, Experimental Brain Research, 1967, 3, 195.

8 Wilkinson, I M S, et al, Fournal of Neurology, Neurosurgery and Psychiatry, $1969,32,367$.
}

${ }^{9}$ Ingvar, D H, and Schwartz, M S, Brain, 1964, 97, 273

10 Ingvar, D, et al, Scandinavian fournal of Laboratory and Clinical Investigation, 1968, 22, supplement 102.

11 Obrist, W D, et al, Neurology, 1970, 20, 315.

12 Simard, D D, et al, Brain, 1971, 94, 273.

13 Ingvar, D H, and Gustafson, L, Acta Neurologica Scandinavica, 1970, 46, supplement 43.

${ }^{14}$ Rothschild, D, Archives of Neurology and Psychiatry, 1942, 48, 417.

15 Corsellis, J A N, Mental Illness and the Ageing Brain. London, Oxford University Press, 1962.

16 Todorov, A B, et al, fournal of the Neurological Sciences, 1975, 26, 81.

17 O'Brien, M D, and Mallett, B L, fournal of Neurology, Neurosurgery and Psychiatry, 1970, 33, 497.

18 Hachinski, V C, et al, Archives of Neurology, 1975, 32, 632.

19 Hachinski, V C, Lassen, N A, and Marshall, J, Lancet, 1974, 2, 207.

20 Gustafson, L, and Hagberg, B, Acta Psychiatrica Scandinavica, 1975, supplement 257.

21 Ingvar, D, Risberg, J, and Schwartz, M S, Neurology, 1975, 25, 964.

22 Hagberg, B, and Ingvar, D H, British fournal of Psychiatry, 1976, 128, 209.

\section{Scoliosis in the myopathies and neuropathies}

In the last decade contributions in the orthopaedic journals on scoliosis have reached a veritable flood, so many are the new developments relating to this old problem. Formerly, the two most common forms-idiopathic scoliosis and paralytic scoliosis-were virtually the only two which concerned surgeons. As over 50 diseases are known to cause scoliosis this was a serious neglect (though understandable), for the pathogenesis of the deformity (which still lacks any explanation) may well be comprehended best by studying some of the rarer types.

In very recent years scoliosis and other orthopaedic problems seen in the myopathies and neuropathies have received intensive and well-merited attention. Two recent books, Spinal Deformity in Neurological and Muscular Disorders ${ }^{1}$ and Scoliosis and Neurological Disease, ${ }^{2}$ have now presented these problems within the limits of our present knowledge of the primary diseases while relating treatment to the tremendous recent advances in the surgical management of scoliosis. Summaries of the problems in the myopathies ${ }^{3-5}$ and neuropathies ${ }^{6}$ have also appeared, while there has also been recent interest in the Kugelberg-Welander syndrome. ${ }^{78}$

From this increasing concern in the problems of scoliosis in these conditions what are we now to think of the problem as a whole and the role of the orthopaedic surgeon in particular? Experience is as yet inadequate to form a final judgment. Individually rare, the inherited neuromuscular diseases are numerous and important; but the experience of one surgeon in the problem of any one disease must be limited. The role of active treatment depends on prognosis, and that requires an accurate diagnosis-a complex problem in the inherited childhood neuropathies. In the inherited myopathies investigation by electromyography and muscle biopsy studied by histochemistry, histology, and electronmicroscopy can now give a reasonably accurate diagnosis.

With rapidly fatal neuropathies such as Werdnig-Hoffman disease no active treatment is indicated, for the infant is doomed. In the dystrophies and neuropathies in which survival to adult life or even a normal life span may be expected the need to manage deformities is not controversial. Reconstruction of crippled feet and the restoration of lost thenar opposition by active tendon transplants is a long-established practice in Charcot-Marie-Tooth disease. The scoliosis of syringomyelia 